\title{
Processos migratórios e letramento na era digital globalizada: entrevista com Catherine Vieira
}

Emerson de Pietril

Aline Akemi Nagata!

\section{RESUMO}

A temática principal que conduz a entrevista refere os processos de letramento na realidade do mundo globalizado, na era digital. Nessa nova ordem, distinta em muitos aspectos da ordem própria à cultura impressa, constituem-se novas possibilidades de se experienciar o espaço e o tempo, produzindo-se novos modos de interação entre sujeitos em torno dos usos da escrita. Os usos da escrita e as práticas de letramento se desenvolvem assim em contextos cujos limites e fronteiras são redefinidos pelo empoderamento resultante da apropriação, pelos sujeitos que deles participam, de dispositivos do mundo letrado. Os recursos técnicos permitem informar à distância, contrastar perspectivas, redimensionar o conhecimento (de si mesmo) em face da diferença, em face do outro, do estrangeiro; permitem, para o imigrante, compor estratégias de permanência no país de destino, e fornecer, para os que ficaram em seu país de origem, subsídios para o desenvolvimento de novas práticas letradas.

\section{PALAVRAS-CHAVE}

Letramento - Migração - Era digital - Globalização. 


\title{
Migration processes and literacy in the global digital age: an interview with Catherine Vieira
}

Emerson de Pietri

Aline Akemi Nagata'

\begin{abstract}
The main subject of this interview is literacy in the digital age, considering migration in the globalized world. Digital culture and its differences in relation to print culture constitute new possibilities of experiencing space and time, which consequently produces new ways of interaction between subjects around the uses of writing. The uses of writing and literacy practices are thus developed in contexts whose limits and boundaries are redefined by the empowerment resulting from the appropriation of the devices of literacy world by those who participate in such contexts. Technical resources allow informing through distances, contrasting different perspectives, rescaling the knowledge (about themselves) when faced with the other, the foreign. They enable the immigrant to compose strategies of permanency in the destination country, and provide those who stayed in their home country with resources for the development of new literacy practices.
\end{abstract}

\section{Keywords}

Literacy - Migration - Digital Era - Globalization.

I- Universidade de São Paulo, São 


\section{INTRODUÇÃO}

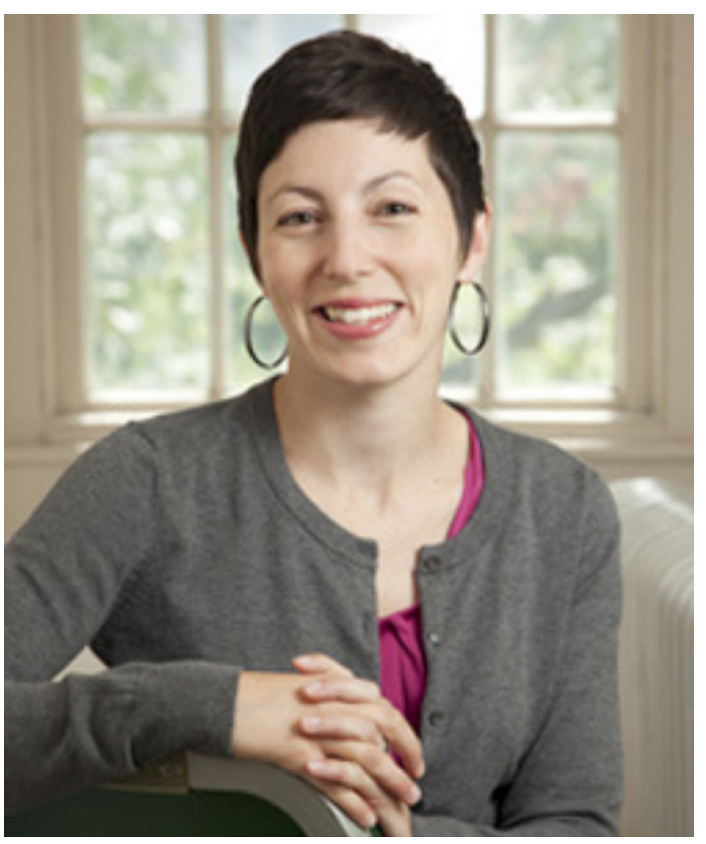

Fonte: arquivos do entrevistado

Professora e pesquisadora do Departamento de Língua Inglesa, na Universidade de WisconsinMadison, Catherine Vieira, ou Kate Vieira, como prefere ser conhecida, esteve na Faculdade de Educação da Universidade de São Paulo, em novembro de 2014, para participar do XIII Seminário de Metodologia do Ensino de Língua Portuguesa. Na ocasião, participou de mesaredonda em que discutiu parte das questões com que se encontra envolvida em suas investigações, principalmente sobre a possibilidade de desenvolvimento de novas práticas de letramento com as interações, mediadas por tecnologias de comunicação, entre imigrantes e aqueles de sua relação que permaneceram em seu país de origem; ou sobre a obtenção, por imigrantes ilegais, de documentos oferecidos por instituições norte-americanas, que possibilitem aos sujeitos uma mais ampla participação social, em face das limitações que a não propriedade do visto de permanência acarreta.

A professora Kate Vieira propõe uma abordagem diferenciada das consequências sociais do letramento. A autora revisita a discussão sobre os impactos que a presença da escrita promoveria sobre a organização social, e sobre as mudanças que a apropriação da tecnologia da escrita produziria sobre a cognição dos indivíduos (GOODY; WATT, 2006). Porém, o faz para evidenciar que, de fato, o desenvolvimento de práticas sociais em que a escrita é uma das funções tem consequências sociais, mas para os modos como se pode apreender a realidade segundo pontos de vista mais relativizados. Isto é: não se trata de considerar que a aquisição da escrita promoveria um desenvolvimento qualitativamente superior de indivíduos e sociedades, com o que se hierarquizariam os mais e os menos civilizados, mas de observar que a apropriação de práticas de letramento, e das tecnologias de comunicação em que elas se realizam, oferecem aos sujeitos a possibilidade de observar a realidade segundo a perspectiva do outro diferente, daquele que é culturalmente diverso, o que favorece o enriquecimento cultural. Essa possibilidade se faria mais produtiva no mundo atual, globalizado e interconectado pelas tecnologias da comunicação.

Assim, trata-se de uma observação das práticas de letramento que amplia os modos como estas têm sido consideradas nos estudos que há pelo menos três décadas (SOARES, 2004) têm se voltado para os usos sociais da escrita. Os estudos do letramento se constituíram em resposta à insuficiência notada no termo alfabetização para a caracterização das relações dos sujeitos com a escrita, quando consideradas as diferentes funções que a escrita desempenha socialmente. Seria preciso não apenas observar a aquisição do sistema de representação escrita da linguagem, para o que o termo alfabetização seria a referência, mas também as diferentes modalidades de uso da escrita considerada a diversidade das esferas de atividade humana.

Com a expansão da cultura digital, outros elementos se introduziram nas discussões sobre letramento, principalmente os referentes às diferentes modalidades com que os sujeitos podem interagir, possibilidade ampliada pelos recursos da comunicação eletrônica. A noção de multiletramentos passou a ser veiculada, então, para se referir às práticas que se desenvolveram 
mais amplamente com a disponibilidade de mídias digitais, e os efeitos que produz principalmente para a esfera educacional, uma vez que a escola, ainda em muito fundamentada nas práticas letradas da cultura impressa, recebe alunos que são provenientes dessa nova cultura multimodal, multiletrada (ROJO, 2012).

As pesquisas da professora Kate Vieira acrescentam a essas proposições a realidade das diferenças sociais, econômicas e culturais, que a expansão dos dispositivos de comunicação eletrônica evidenciou em bases novas. A imigração, em tempos de globalização econômica, move mais rapidamente a desigualdade social de um espaço geográfico a outro, nos movimentos que os sujeitos perfazem em sua busca por melhores condições de vida. Neste mesmo momento histórico, se encontram disponíveis meios para que os rastros produzidos pelo movimento dos sujeitos possam ser registrados e compartilhados em velocidades que promovem a redução do tempo (SANTOS, 2000). A percepção das diferenças pelos sujeitos que delas participam, como aponta a professora Kate Vieira, numa das observações que faz na entrevista, se realiza assim de modo mais impactante, e evidencia a esses sujeitos suas condições de vida pelo contraste entre as condições existentes em seu país de origem, e as condições que encontram no país para onde imigraram.

Os efeitos desse contraste não permanecem mais restritos à vivência do imigrante, que antes apenas poderia narrar sua experiência oralmente, aos mais próximos, ou o faria com o uso da escrita datilografada ou manuscrita, remetida pelo correio convencional, aos que permaneceram em seu país de origem. As mudanças decorrentes da participação do imigrante numa outra cultura podem produzir efeitos mais rapidamente sobre seu lugar de origem e sobre as pessoas de seu contato social que lá convivem. 0 contato on-line, com o uso de equipamentos e serviços que permitem a comunicação síncrona, inclusive, favorece a interação e a troca por vezes quase instantânea de informações de ordens diversas: culturais, sociais, econômicas etc.

Trata-se, portanto, de observar-se a imigração e o contato com a cultura estrangeira como um processo que não apenas se define por fatores econômicos, quer no que respeita ao deslocamento em direção ao estrangeiro em busca de melhores condições financeiras, quer no que respeita ao envio, aos que permaneceram no país de origem, de recursos para garantir a subsistência destes. Trata-se, também, de se inserir em práticas de letramento próprias à cultura em que se está ingressando, de se apropriar dessas práticas para que possam ser construídas estratégias de sobrevivência nesse novo contexto. É assim um processo de aprendizagem cujos efeitos se compartilham e impactam a cultura de origem do imigrante.

Mostra-se necessário, na cultura que se constitui a partir da mais ampla distribuição das tecnologias de comunicação eletrônica, conhecer as consequências sociais do letramento em condições de produção discursiva que possibilitam novos modos de interação entre sujeitos, seja no que se refere à sua aproximação no tempo e no espaço, seja no que se refere ao recurso a diferentes modalidades de linguagem, disponíveis nos suportes eletrônicos e nas plataformas digitais. As pesquisas da professora Kate Vieira nos convidam a adentrar nesse estado de coisas cuja atualidade por vezes não permite, aos que dele participam, perceber mais claramente seus modos de organização e suas relações com as diferenças políticas, sociais, econômicas e culturais do mundo de hoje.

\section{REFERÊNCIAS}

GOODY, Jack; WATT, lan. As consequências do letramento. São. Paulo: Paulistana, 2006.

ROJO, Roxane. Pedagogia dos multiletramentos: diversidade cultural e de linguagens na escola. In: ROJO, Roxane; MOURA, Eduardo (Org.). Multiletramentos na escola. São Paulo: Parábola, 2012. p. 11-31.

SANTOS, Milton. Por uma outra globalização: do pensamento único à consciência universal. São Paulo: Record, 2000.

SOARES, Magda. Letramento e alfabetização: as muitas facetas. Revista Brasileira de Educação, Rio de Janeiro, n. 25, p. 5-17, abr. 2004. 


\section{A ENTREVISTA}

Gostariamos de conhecer um pouco sobre sua formação para a pesquisa, sua trajetória acadêmica, e como se interessou pelos temas de que tem tratado em suas investigações, no que se refere aos processos de letramento entre fronteiras, possibilitados pelos processos migratórios.

Estou realmente honrada em ser entrevistada por Educação e Pesquisa.

Obrigada pela pergunta. Eu tenho duas respostas. Uma de caráter mais pessoal e outra de caráter mais profissional! Pessoalmente, eu fui educada em uma comunidade de imigrantes, de açorianos e de libaneses, em Massachusetts. Essa comunidade, por razões ligadas às condições regionais de trabalho, circunstâncias de migração, e de desigualdade de gênero e classe, realmente lutou pela educação e pelo letramento em particular. 0 pior insulto que se poderia ouvir era "iletrado". "Iletrado" significava "você não pertence". Para mim, à época, havia sempre uma conexão entre migração e letramento. 0 letramento parecia ser uma maneira de sair, acima ou além das circunstâncias limitantes, especialmente em comunidades de imigrantes. Então, esse assunto tem um apelo pessoal.

No que se refere aos aspectos profissionais, depois de conseguir minha licenciatura em Inglês, com especializações em francês e alemão (Eu sempre amei línguas!), lecionei inglês no ensino médio na Letônia por dois anos. Essa escola ficava em uma comunidade imigrante de língua minoritária, para a qual as pessoas emigraram ou foram enviadas de toda a União Soviética - Bielorrúsia, Georgia, Ucrânia, Rússia etc. Essa experiência me sensibilizou para questões de linguagem e política, particularmente em terrenos politicamente tumultuados.

Depois da Letônia, eu retornei aos EUA e lecionei Inglês e Estudos Sociais no quinto e sexto anos em uma comunidade prioritariamente de imigrantes mexicanos em Dallas, Texas. A escola ficava em uma comunidade pobre, do outro lado da ponte que levava ao brilhante e rico centro de Dallas. A desigualdade econômica era brutalmente visível. Eu não posso dizer que era uma boa professora primária. Eu lutava. Mas então meus colegas e eu fizemos visitas domiciliares, falamos com as famílias, ouvimos suas preocupações. E isso foi um ponto de virada para mim, como jovem professora. Eu percebi que, para que qualquer tipo de letramento seja eficaz, particularmente em comunidades marginalizadas, eu tinha que entender questões de raça, classe, história e família.

Quando decidi fazer meu doutorado e vim para a pós-graduação, eu fiquei grata por conhecer minha orientadora Deborah Brandt, que me ajudou a entender essas experiências em uma perspectiva teórica e metodológica. Então, agora eu estudo práticas de letramento de imigrantes e as comunidades que eles deixam para trás, com o olhar voltado para como os contextos maiores de classe social, história, política e economia moldam o uso diário do letramento. Estou convencida, pelo meu treinamento profissional e experiências pessoais de que letramento, migração e comunidade dependem uns dos outros de formas tão complexas que necessitam ser investigadas.

As relações entre letramento e processos migratórios, que você observa em seus estudos, são algo que se tornou possivel com as novas tecnologias de editoração de textos e de comunicação digital, que permitem o contato de pessoas distantes no espaço (e no tempo), ou são algo que se acelerou e se modificou na atualidade, mas que já havia antes com outras práticas? Isto é: as práticas de letramento que você observa são práticas constituídas no mundo digital, ou podemos considerá-las existentes, em outras bases, também na cultura impressa?

Sim, existe uma linha histórica fascinante entre o letramento impresso e o digital, 
particularmente em contextos transnacionais! Um dos tópicos que tenho acompanhado em minha nova pesquisa é em que medida letramento e migração se interligaram por algum tempo. Um maravilhoso estudo recente de Martin Lyons mostra que a migração na virada do século XX na Europa promoveu letramento em massa entre os camponeses. Pessoas aprenderam a escrever cartas porque sentiam falta de seus entes queridos! Eles aprenderam a escrever para se conectar através da distância, para resolver o difícil problema de corpos sendo separados, para matar saudades ${ }^{1}$. Quando pessoas não podem viajar, envelopes podem, potencialmente promovendo o letramento em famílias transnacionais.

Então, o que estou tentando fazer agora (com apoio da Universidade de Wisconsin e da Fundação Spencer) é entender como processos similares podem ou não funcionar em uma era digital. Tenho feito pesquisa com membros de famílias de imigrantes, em uma comunidade no Brasil marcada pela emigração moderada, e em uma comunidade na Letônia, marcada pela emigração em massa, para ter uma perspectiva comparativa de como a emigração pode promover (ou não) letramento digital. 0 que descobri é que quase todos os participantes experimentam um ligeiro aumento no letramento digital quando alguém migra. Tal conhecimento, além disso, está ligado à economia, que frequentemente promove a migração em primeiro lugar. Então, migrantes geralmente enviam para casa o que tenho chamado de remessas escritas, como laptops, webcams, ou conhecimento sobre determinado software, para facilitar a comunicação com familiares deixados para trás. Famílias se apropriam dessas tecnologias, as incorporam em suas práticas existentes, e aprendem a usá-las.

Esclarecendo, eu não estou dizendo que toda tecnologia boa e avançada provém de migrantes em países supostamente "desenvolvidos". Pelo contrário, o fator distância e o fator desigualdade econômica

\footnotetext{
1- Aqui a professora Kate Vieira utiliza de fato a expressão em português.
}

global, tomados juntos, criam esses circuitos transnacionais de remessas letradas. É uma troca econômica e interpessoal, com consequências sobre como os moradores locais estão usando o letramento em suas vidas ${ }^{2}$.

Retornando à questão inicial, sim, há uma base histórica e material no letramento impresso para entender algumas das tendências no letramento digital. Muitas das pessoas que entrevistei para esse projeto estavam se comunicando transnacionalmente antes da internet. Então, suas experiências de letramento impresso estão submersas em suas práticas digitais. $\mathrm{Na}$ vida das pessoas, o impresso e o digital se entrecruzam. Pontualmente, o que permanece igual, e o que difere, é como o letramento impresso e o digital estão se interanimando em nosso momento histórico corrente, em que as pessoas se movem ao redor do globo rapidamente e a desigualdade social permanece arraigada. Essa é uma questão premente para os estudiosos do letramento.

Há discussões atuais a respeito da hiperdiversidade (a coexistência de várias culturas e de suas línguas num determinado país, mantendo parte de suas características de origem). Em sua pesquisa, você observa de que modo as práticas de letramento favorecidas pelas novas tecnologias se produzem nas interações entre imigrantes em suas relações com seus familiares, em seus países de origem. Há impactos dessas práticas de letramento sobre os países que recebem os imigrantes, em razão das atividades sociais desses imigrantes?

Essa é uma questão excelente e minha resposta é: não tenho certeza. Sou grata por ter recebido financiamento da Universidade de Wisconsin para coletar dados nesse verão nos EUA, e explorar algumas dessas mesmas questões. 0 que é que os próprios imigrantes estão fazendo com as tecnologias que utilizam para se comunicar com membros da família

2- 0 endereço do site do projeto na internet é o http://www. literacyandimmigration.com/. 
na terra natal? Quais novos letramentos eles aprendem com aqueles que ficam para trás nessas interações? E como isso importa para eles e para o cenário do letramento do país anfitrião?

Essas questões são importantes porque muito do discurso popular sobre imigração e letramento, nos EUA pelo menos, gira em torno da "assimilação", a ideia de que imigrantes devem aprender Inglês para se assimilarem a uma convenção. 0 problema com os usos de letramento assimilacionistas, no entanto, é que eles são frequentemente usos racistas do letramento. Por exemplo, os EUA costumavam testar o letramento em Inglês de imigrantes na fronteira, com o objetivo de prevenir a entrada daqueles imigrantes considerados insuficientemente "brancos" para assimilar. E existem muitos outros exemplos de como o letramento vem sendo usado para perpetuar uma ideologia da supremacia branca. Parte da importância do trabalho político e empírico associado à hiperdiversidade, a meu ver, é que ele contraria mitos sobre assimilação. Ele muda o foco para como as práticas de letramento dos países anfitriões estão mudando por causa da influência produtiva de imigrantes, que trazem consigo diversas experiências educacionais. Estou ansiosa para aprender sobre como essas experiências educacionais diversas são em parte desenvolvidas depois que os migrantes migraram, e continuam a se comunicar e interagir com a família e a cultura do país de origem, de maneiras que se tornaram possíveis pelas tecnologias digitais.

Em relação aos imigrantes, você trata dos modos como ter acesso a práticas de letramento pode contribuir com essas pessoas, para que elas possam responder às necessidades de viver num país estrangeiro sem estar legalizadas. 0 que você observa, de seus contatos com seus sujeitos de pesquisa, sobre estar num país estrangeiro, sem as possibilidades de acesso à legalidade de sua permanência nesse país? Há apenas problemas nisso, ou você percebe vantagens também? Isto é: poder desenvolver práticas de letramento que não se desenvolveriam caso estivessem legalizados seria também um ganho cultural para essas pessoas?

Ou é de fato algo instrumental: 0 acesso a determinadas práticas de letramento é algo para se conseguir melhores condições de vida no país em que se está ilegalmente?

Para mim, é difícil pensar nos benefícios de ser ilegal nos EUA. Os imigrantes ilegais que compartilham suas vidas comigo para minha pesquisa enfrentam o temor constante da deportação, da separação familiar, até mesmo da morte. Somente agora os pesquisados começam a entender o trauma psicológico de viver em circunstâncias indutoras de ansiedade como essas.

Em termos de efeito da ilegalidade no letramento, eu descobri que, para muitos, a visão de letramento tornou-se realmente conectada aos papéis - vistos, Green Cards e passaportes. Esses artefatos letrados, documentos, eram tão valiosos, tão importantes, tão cruciais à sobrevivência e bem-estar, que influenciavam a forma como as pessoas entendiam e usavam o letramento mais amplamente. Então, por exemplo, para algumas pessoas ilegais, elas não tinham documentos, portanto, não podiam participar politicamente em espaços públicos. Mas, quando iam à igreja, elas ofereciam cartões missionários, que lhes davam uma licença para escrever sermões e hinos religiosos, para pregar. Essencialmente, o letramento delas operava em uma lógica de burocracia e documentos.

Dentro dessas circunstâncias textuais hostis, o aprendizado ou não de Inglês era algo secundário para muitas pessoas. Como uma jovem ilegal me disse, " 0 inglês não era o problema”. 0 problema eram os documentos. Sem produtos materiais letrados, documentos, o letramento em inglês não faz muito pelos imigrantes. No final, o inglês pode ser aprendido! Conseguir os documentos legais era muito mais difícil, mais preocupante. 
Voltando à sua questão, se há qualquer benefício ao letramento em ser ilegal, é que as pessoas ilegais nos meus estudos realmente apreciaram a natureza instrumental do letramento, e também, em algum nível, o seu absurdo. Com o documento certo, tem-se certos privilégios e direitos cruciais, e sem ele, pode-se ser destituído desses direitos. É um absurdo que Estados modernos incutam documentos com tanto poder, que as fronteiras sejam policiadas, ao menos em parte, por documentos. 0 que não quer dizer que ilegais não escrevam expressiva ou socialmente. Pessoas escreviam apaixonadamente, por exemplo, sob o amparo das igrejas que os documentaram. Mas essa escrita sempre foi instruída pelos regimes textuais maiores que regulavam as mobilidades dos imigrantes.

Em lugar de apenas observar o empoderamento que o letramento oferece, você observa também a opressão que práticas letradas podem representar. Para os imigrantes, apropriar-se de práticas letradas é de um modo de resistir à adversidade encontrada em países estranhos. A promoção do letramento nos países de origem, pelo acesso a novas práticas de letramento, favorece a atuação política desses sujeitos, de modo a transformar situações que os oprimem em seus próprios países?

Pelo que percebi até agora, as pessoas estão investindo em aprendizado letrado imigrante-dirigido, em formas que vão ao encontro de seus interesses sociais e econômicos. 0 que significa trabalhar em dois níveis diferentes. Um é o nível do conteúdo remetido por cartas, e-mails, e chats em vídeo, pelos quais os moradores da terra natal estão desenvolvendo o que estudiosos transnacionais chamam de perspectiva bifocal. Essa é a capacidade de ver as circunstâncias de um em relação à de outras nações ou culturas. Então, por exemplo, um homem (eu o chamarei de Felipe), um professor, cujo irmão estava morando fora e lutando, disse o seguinte de uma carta que recebeu de seu irmão: "Um dia, meu irmão nos disse que só tinha uma batata para o almoço e uma batata para o jantar. Enquanto ele escrevia isso em uma carta, em casa, nós tínhamos uma panela com feijão e arroz e uma tonelada de comida. Ficamos tristes, porque é meu irmão"

A carta do irmão de Felipe transformou uma refeição típica em um exemplo de privilégio relativo. De repente, pareceu a Felipe que havia uma montanha de comida na panela. Essa bifocalidade, por sua vez, informa as interações de Felipe com seus alunos, que, como ele diz, "estão passando por muitas dificuldades, alunos que nunca viram outros lugares além da cidade em que vivem, de seu país, mas que podem então perceber que não só eles passam por dificuldades”...

Felipe nunca viajou para fora do Brasil. Sua perspectiva mais ampla vem de sua conexão textual mediada com seu irmão, que o diferencia de seus alunos lutadores. Então, sua visão bifocal foi difundida, divulgada em novo contexto.

Além do conteúdo, outra tendência que tenho notado é que as pessoas estão investindo e fazendo circular seu conhecimento sobre como usar certas tecnologias. Então, por exemplo, um outro homem, Hugo, recebeu uma webcam de sua irmã que mora na Europa, e se tornou o primeiro a aprender a usá-la em sua área, fazendo da sua casa uma espécie de centro de prática tecnológica. Pessoas paravam, usavam o computador, e ele investia seu conhecimento em troca de status social. Para mim, isso realmente ressoou como as histórias das primeiras agências de correio, onde a possibilidade de se conectar com pessoas à distância intensamente promoveria interações sociais locais.

Além disso, Hugo, que estava familiarizado com computadores, em parte por sua prática de comunicação com sua irmã no exterior, também pode trabalhar de forma independente como consultor técnico de computadores, trabalhando com clientes internacionalmente com seus problemas tecnológicos. Então ele trabalhava com clientes não somente no Brasil, mas nos Estados Unidos. 
A ideia aqui é que a migração está promovendo certas formas de aprendizado letrado, que depois as pessoas fazem circular, recircular, e ganham com isso. E existem muitos exemplos mais desse modelo.

Para ser clara, a ideia não é que o letramento do exterior é de alguma forma melhor que os letramentos locais - absolutamente! Eu quero evitar analisar esse fenômeno como uma forma de narrativa de recolonização. Para Hugo, de fato, os recursos de letramento fluíam do norte do globo para o sul do globo e vice-versa. Eu penso que esses fluxos são complexos e que o letramento talvez possa ganhar ou perder valor conforme ele se move. De qualquer forma, o que está acontecendo é que o aprendizado letrado imigrante-dirigido está ajudando algumas pessoas a encontrarem algumas pressões locais para desenvolverem práticas digitais letradas e perspectivas globalizadas. Pessoas as tomam e as usam em conjunção com outras demandas letradas inspirando suas vidas.

Para os participantes com os quais trabalhei, ninguém estava realmente usando aprendizado letrado imigrante-dirigido politicamente, mas o estavam usando social, econômica e pedagogicamente. Então, a possibilidade para a ação política existe.

Você estuda os impactos do letramento em países diferentes (Letônia e Brasil). Há diferenças de um país a outro (um na Europa, outro na América do Sul), ou as práticas de letramento desenvolvidas em função dos processos de imigração têm características similares? 0 que se assemelharia e o que diferiria de um país a outro?

Confira isso comigo depois, por favor ainda não terminei minha análise comparativa! Mas tenho como palpite que as práticas letradas migrante-dirigidas são informadas pela distância da migração. Então, os brasileiros tendem a migrar mais para os EUA e o Japão, por exemplo. Os letões tendem a migrar para locais próximos, dentro da União Europeia.
Então, é possível que o fato de poder voltar para casa em visitas razoavelmente baratas e rápidas possa moldar a forma como as pessoas usam o letramento para se comunicar e também a sua importância. Certamente, outros fatores podem ser culturais: quem mais tem uma palavra como saudade? Ou políticos: a história da Letônia como um ex-estado soviético e a do Brasil como um país receptor de imigrantes. $\mathrm{Ou}$ ainda econômicas: o status do Brasil como uma potência mundial etc.

Há algo nos processos de letramento que você observa que seria comum entre os países em que realiza sua pesquisa? Há algo nesses processos de letramento que seria característico da atual ordem mundial, pois tornado possível em razão dos processos de globalização? $\mathrm{Ou}$ não: trata-se não de algo generalizável, mas de algo específico de cada contexto em que possa vir a ocorrer?

Sim para a primeira questão! Eu penso que duas das mais prementes tendências voltadas para o letramento hoje são os movimentos transnacionais de pessoas e as mudanças rápidas de tecnologias de letramento, e ambas estão ligadas à desigualdade econômica. As Nações Unidas relataram que 232 milhões de pessoas vivem atualmente fora de seus países de nascença, e que as taxas de imigração subiram 33\% desde 2000. Esse é um número enorme de pessoas que estão encontrando o que o sociolinguista Jan Blommaert chamou de diferentes regimes letrados em novos países. Ou seja, elas estão frequentemente encontrando novas burocracias, novas formas de usar o letramento, novas linguagens, novos padrões, novos preconceitos linguísticos. E depois há o impacto nas famílias deixadas para trás, que às vezes dependem de remessas de dinheiro, dos familiares, para pagar pela educação, e que estão usando novas tecnologias digitais letradas para se comunicar com familiares trabalhando no exterior. Então, sim, eu penso que a desigualdade econômica global, que frequentemente leva à migração, 
associada às taxas de desenvolvimento de novas tecnologias de comunicação, estão moldando, de forma muito macro, os modos como as pessoas estão experimentando o letramento. Ao mesmo tempo, claro, o letramento ocorre, para as pessoas comuns, em contextos específicos, em famílias, em lares, mas esses contextos sociais locais são sempre ligados e afetados por tendências maiores. 0 letramento é ao mesmo tempo macrossocial e microssocial, político e pessoal, global e local, o que em parte é o que lhe dá poder na vida das pessoas. Os processos de globalização, eu acredito, desnudam esses atributos do letramento.

\section{BIBLIOGRAFIA DA ENTREVISTADA}

LORIMER-LEONARD, Rebecca; VIEIRA, Kate; YOUNG, Morris. Introduction: principles of transnational inquiry for literacy in composition studies. Literacy in Composition Studies, San Bernardino, no prelo.

VIEIRA, Kate. 'American by paper': assimilation and documentation in a biliterate bi-ethnic immigrant community. College English, Illinois, v. 73, n. 1, p. 50-72, Sep. 2010.

VIEIRA, Kate. American by paper: how documents matter in immigrant literacies. Minnesota: University of Minnesota Press, no prelo.

VIEIRA, Kate. Literacy learning in migrants' homelands. Dispnível em: <www.literacyandimmigration.com>. Acesso em: 2015.

VIEIRA, Catherine. Minding the gap: realizing our ideal community writing center. with Julia Doggart and Melissa Tedrowe. Community Literacy Journal, v. 1, n. 2, p. 71-80, 2007.

VIEIRA, Kate. On the social consequences of literacy. Literacy in Composition Studies, v. 1, n. 1, p. 26-32, Mar. 2013.

VIEIRA, Kate. Response. In: FLYNN, Elizabeth et al. (Ed.) Feminist rhetorical resilience. Utah: Utah State University Press, 2012. p. 89-90.

VIEIRA, Kate. The traveling fado. In: Feminist rhetorical resilience. Utah: Utah State University Press, 2012. p. 59-81.

VIEIRA, Kate. Undocumented in a documentary society: textual borders and transnational religious literacies. Writing in a Global Context, v. 28, n. 4, p. 436-461, Oct. 2011. Special issue of written communication. 